\title{
Vitamin D increases glucocorticoid efficacy via inhibition of mTORC1 in experimental models of multiple sclerosis
}

\author{
Robert Hoepner ${ }^{1}$ (D) Maud Bagnoud ${ }^{1} \cdot$ Maximilian Pistor ${ }^{1,2} \cdot$ Anke Salmen $^{1} \cdot$ Myriam Briner $^{1} \cdot$ Helen Synn $^{3} \cdot$ \\ Lisa Schrewe ${ }^{1} \cdot$ Kirsten Guse $^{1} \cdot$ Farhad Ahmadi $^{1} \cdot$ Seray Demir ${ }^{2} \cdot$ Louis Laverick $^{4} \cdot$ Melissa Gresle $^{4} \cdot$ Paul Worley $^{5}$. \\ Holger Michael Reichardt ${ }^{6} \cdot$ Helmut Butzkueven $^{7} \cdot$ Ralf Gold $^{2} \cdot$ Imke Metz $^{3} \cdot$ Fred Lühder $^{8} \cdot$ Andrew Chan ${ }^{1}$
}

Received: 7 December 2018 / Revised: 31 March 2019 / Accepted: 20 April 2019 / Published online: 27 April 2019

(c) The Author(s) 2019

\begin{abstract}
The limited efficacy of glucocorticoids (GCs) during therapy of acute relapses in multiple sclerosis (MS) leads to long-term disability. We investigated the potential of vitamin $\mathrm{D}$ (VD) to enhance GC efficacy and the mechanisms underlying this VD/ GC interaction. In vitro, GC receptor (GR) expression levels were quantified by ELISA and induction of T cell apoptosis served as a functional readout to assess synergistic $1,25(\mathrm{OH})_{2} \mathrm{D}_{3}(1,25 \mathrm{D}) / \mathrm{GC}$ effects. Experimental autoimmune encephalomyelitis $\left(\mathrm{MOG}_{35-55}\right.$ EAE) was induced in mice with T cell-specific GR or mTORc1 deficiency. 25(OH)D (25D) levels were determined in two independent cohorts of MS patients with stable disease or relapses either responsive or resistant to GC treatment (initial cohort: $n=110$; validation cohort: $n=85$ ). Gene expression of human $\mathrm{CD}^{+} \mathrm{T}$ cells was analyzed by microarray $(n=112)$ and correlated with $25 \mathrm{D}$ serum levels. In vitro, $1,25 \mathrm{D}$ upregulated GR protein levels, leading to increased GC-induced T cell apoptosis. 1,25D/GC combination therapy ameliorated clinical EAE course more efficiently than respective monotherapies, which was dependent on GR expression in T cells. In MS patients from two independent cohorts, 25D deficiency was associated with GC-resistant relapses. Mechanistic studies revealed that synergistic 1,25D/GC effects on apoptosis induction were mediated by the mTOR but not JNK pathway. In line, 1,25D inhibited mTORc1 activity in murine T cells, and low 25D levels in humans were associated with a reduced expression of mTORc1 inhibiting tuberous sclerosis complex 1 in $\mathrm{CD}^{+} \mathrm{T}$ cells. GR upregulation by 1,25D and 1,25D/GC synergism in vitro and therapeutic efficacy in vivo were abolished in animals with a T cell-specific mTORc1 deficiency. Specific inhibition of mTORc1 by everolimus increased the efficacy of GC in EAE. 1,25D augments GC-mediated effects in vitro and in vivo in a T cell-specific, GR-dependent manner via mTORc1 inhibition. These data may have implications for improvement of anti-inflammatory GC therapy.
\end{abstract}

Keywords Mammalian target of rapamycin $\cdot$ Steroid resistance $\cdot$ Calcitriol $\cdot$ c-Jun $\mathrm{N}$-terminal kinase $\cdot$ Relapse treatment

Electronic supplementary material The online version of this article (https://doi.org/10.1007/s00401-019-02018-8) contains supplementary material, which is available to authorized users.

Robert Hoepner

robert.hoepner@insel.ch

Andrew Chan

andrew.chan@insel.ch

1 Department of Neurology, Inselspital Bern, University Hospital, University of Bern, Bern, Switzerland

2 Department of Neurology, St. Josef Hospital, Ruhr University Bochum, Bochum, Germany

3 Institute of Neuropathology, University Medical Center Goettingen, Goettingen, Germany

4 Department of Medicine, Royal Melbourne Hospital, University of Melbourne, Melbourne, Australia
5 The Solomon H. Snyder Department of Neuroscience, School of Medicine, John Hopkins University, Baltimore, USA

6 Institute for Cellular and Molecular Immunology, University Medical Center Goettingen, Georg-August-University Goettingen, Goettingen, Germany

7 Department of Neuroscience, Central Clinical School, Alfred Campus, Monash University, Melbourne, Australia

8 Institute of Neuroimmunology and Multiple Sclerosis Research, University Medical Center Goettingen, Georg-August-University Goettingen, Goettingen, Germany 


\section{Introduction}

Multiple sclerosis (MS) is an autoimmune disorder of the central nervous system. At disease onset, more than $80 \%$ of MS patients suffer from a relapsing disease course [15]. MS relapses are characterized by acute occurrence of new neurological symptoms or worsening of pre-existing deficits due to acute focal autoimmune inflammation. Relapses often lead to sustained residual disability with almost $50 \%$ of patients suffering increased disability post-relapse [26]. High-dose intravenous glucocorticoid (GC) pulse therapy, i.e. 500-2000 mg methylprednisolone (MP) over 3-5 days, is the current standard treatment of acute MS relapses. A plethora of experimental data indicates that termination of the autoimmune inflammatory reaction by GCs attenuates tissue damage [27]. Several mechanisms are considered to contribute to these profound anti-inflammatory effects, e.g. inhibition of pro-inflammatory mediators, inhibition of activation and migration of immune cells, and restoring integrity of the blood-brain barrier [27, 46]. Induction of $T$ cell apoptosis in both MS patients and experimental autoimmune encephalomyelitis (EAE), an animal model that mimics many features of MS, is also considered to contribute to the therapeutic mechanism of GCs [23, 44]. In EAE, GC efficacy is dependent on the presence of the glucocorticoid receptor (GR) expressed in $\mathrm{T}$ cells $[52,54]$. Although GCs constitute the mainstay of relapse therapy in MS, a considerable proportion of patients do not respond sufficiently [6]. This impaired clinical efficacy has been linked to altered levels of the GR and associated proteins [2]. Namely, reduced expression of the GR in peripheral blood mononuclear cells of GC-resistant MS patients was accompanied by increased levels of the chaperone heat shock protein (hsp) 90 [29]. In addition, a downregulation of the GR was detected in GCresistant $\mathrm{T}$ cells obtained during myelin oligodendrocyte glycoprotein $_{35-55}\left(\mathrm{MOG}_{35-55}\right)$ EAE [14]. Clinically, overcoming GC resistance remains an unmet need in MS therapy. Several lines of evidence indicate that vitamin D (VD) could augment GC-induced immune effects. For instance, VD pre-treatment increased dexamethasone-induced binding of the GR to GC response elements in monocytes from patients with GC-resistant asthma [57]. Furthermore, VD restored the efficacy of GCs to induce IL-10 production in T-helper cells [55]. Hypothetically, the inhibition of mammalian target of rapamycin (mTOR) by VD could mediate such a synergistic effect, since in malignant lymphoid cells in vitro resistance to GCs appears to be reversible after application of the mTOR inhibitor rapamycin [31]. The mTOR pathway controls cell differentiation and survival by integrating multiple environmental cues such as stress, oxygen supply, growth factors and amino acids. In particular, mTORc1 regulates cell metabolism and growth, whereas mTORc2 affects cell proliferation and survival in a cell-type-specific manner [42]. Inhibition of mTOR by VD was previously described in osteoblasts [25] and more recently it was also demonstrated that VD administration downregulates mTOR in $\mathrm{CD} 4^{+} \mathrm{T}$ cells during rat EAE [56]. As an alternative pathway, c-Jun N-terminal kinases (JNK) pathway has also been implicated in the regulation of GR expression [51]. JNK belongs to a highly preserved ubiquitous signaling pathway, the mitogen-activated protein (MAP) kinases [41] and activation of JNK was found to be associated with a poor response to GCs in patients with Crohn's disease [41]. Here, we set out to investigate the potential synergistic effects of VD and GCs in vitro, in EAE and in MS patients in the context of acute relapses, and to unravel the cellular and molecular mechanisms underlying the effects of VD on GC therapy. We found that VD increases the efficacy of GC treatment by upregulating the GR via mTORc1 in T cells but not by JNK signaling, which suggests that combination therapy with mTOR inhibiting substances bears the potential to overcome GC resistance in the treatment of MS relapses.

\section{Materials and methods}

The active metabolite $1,25(\mathrm{OH})_{2} \mathrm{D}_{3}(1,25 \mathrm{D})$ was used in all in vitro and in vivo studies. Further, it was measured in murine serum samples to assess bioavailability after oral gavage of $1,25 \mathrm{D}$. For human serum concentrations, 25-hydroxyvitamin D (25D) was analyzed as it represents the body's VD supply [18].

\section{Studies with human samples}

Human studies were approved by the cantonal ethics committee Bern and the local ethics committee of Ruhr-University Bochum and Goettingen (5408-15, 4801-13, 201700060, 2017-01369, E08-910, 19-09-10). CD3 ${ }^{+} \mathrm{T}$ cells were isolated using gradient centrifugation and negative magnetic cell sorting (Pan T cell isolation kit ${ }^{\circledR}$, Miltenyi Biotec, Cologne, Germany). $1 \times 10^{6} / \mathrm{ml}$ T cells (RPMI, Invitrogen, Karlsruhe, Germany; 10\% FCS, Sigma-Aldrich, St. Louis, USA; $1 \%$ Penicillin/Streptomycin (PenStrep), Invitrogen; L-Glutamine, Invitrogen, Sigma-Aldrich) were stimulated with phytohemagglutinin (PHA, $0.5 \mu \mathrm{g} / \mathrm{ml}$, SigmaAldrich) and treated with control (solvent: 0.1\% DMSO), $10 \mathrm{nM}$ 1,25D (MedChem Express, South Brunswick, New Jersey, USA) or $75 \mu \mathrm{M}$ methylprednisolone (MP, MIBE $\mathrm{GmbH}$, Brehna, Germany) or the combination of 1,25D/MP $\left(37{ }^{\circ} \mathrm{C}, 5 \% \mathrm{CO}_{2}\right)$. Furthermore, the mTOR inhibitors rapamycin (5.5 nM, Millipore, Darmstadt, Germany), voxtalisib (1.57 $\mu \mathrm{M}$, MedChemExpress), and everolimus ( $2 \mathrm{nM}$, Seleck 
Chemicals, Houston, Texas USA) as well as the JNK inhibitor SP600125 (10 nM, MedChem Express) were used alone or in combination with $75 \mu \mathrm{M}$ MP. T cell apoptosis was analyzed by flow cytometry (FACS) after 24 or $72 \mathrm{~h}$ (annexin V/ propidium iodide, Becton-Dickinson Bioscience, Franklin Lakes, New Jersey, USA). For the analysis of GR expression, $\mathrm{CD}^{+} \mathrm{T}$ cells $\left(1 \times 10^{6} / \mathrm{ml}\right)$ from healthy donors (HD, $\left.n=6\right)$ were seeded in a poly-L-lysine-coated 96 -well plate $(10 \mu \mathrm{g} /$ $\mathrm{ml}$, Sigma-Aldrich). Cells were treated with control (solvent: $0.1 \%$ DMSO) or $1,25 \mathrm{D}$ for $24 \mathrm{~h}\left(10 \mathrm{nM}, 100 \mathrm{nM} ; 37^{\circ} \mathrm{C}, 5 \%\right.$ $\mathrm{CO}_{2}$ ), and the GR was quantified by ELISA according to the manufacturer's protocol (NR3C1 Human Cell-Based ELISA kit, Abnova, Taipei, Taiwan). Data are expressed as ratio of optic density (OD) ${ }_{450}$ GR/glyceraldehyde 3-phosphate dehydrogenase (GAPDH)

To test whether the GR is differentially regulated in different $T$ cell subsets, human GR was analyzed by western blot in $\mathrm{CD}^{+}$and $\mathrm{CD}^{+} \mathrm{T}$ cells. Cells were isolated from frozen PBMC collected after GC administration (negative selection; CD4 ${ }^{+} \mathrm{T}$ Cell Isolation Kit, human; $\mathrm{CD}^{+} \mathrm{T}$ Cell Isolation Kit, human; Miltenyi Biotec; Germany). After lysis (10\% trichloroacetic acid buffer, Fluka, Switzerland), western blots were stained with following antibodies and analyzed with Fusion Imaging System (Vilber Lourmat, France): Anti-GR, 1:50,000 (abcam, United Kingdom); Anti-HSP90, 1:1000 (Cell Signaling, Massachusetts); AntiGAPDH, 1:10,000 (abcam, United Kingdom); Goat AntiRabbit IgG (H + L) HRP, 1:3000 (Bio-Rad, California). In addition, early active demyelinating MS lesions, obtained via stereotactic biopsy before GC administration, were costained for GR and either CD3, CD4 or CD8. The following antibodies were used for staining of paraffin slices: AntiGR, 1:300 (Cell Signaling Technology); Anti-CD3, 1:50 (Zytomed System, Berlin, Germany); Anti-CD4, 1:100 (Zytomed System); Anti-CD8, 1:250 (CellMarque, Rocklin, USA) [30].

A retrospective chart analysis identified stable MS patients (initial cohort; University of Bochum, $n=56$, McDonald criteria; relapsing phenotype, no relapse or intravenous GCs within the last 3 months) and MS patients during acute relapse (initial cohort: $n=54 ;<30$ days since symptom onset). An independent validation cohort included $n=85$ patients (stable MS, $n=40$; MS relapse, $n=45$, University of Bern). Relapse definition followed standard criteria [13]. Patients were defined as GC responsive if they no longer showed relapse-associated neurological symptoms within 2 months from relapse onset (initial cohort $n=30$; validation cohort $n=20$ ) [17]. In line with current guidelines [13], patients with insufficient clinical response as defined by clinical experts (e.g. visual acuity $<0.5$ or EDSS pyramidal functional subscore $>3$ ) to $\geq 2$ high-dose GC pulses (e.g. 500-2000 mg MP over 3-5 days) underwent treatment intensification with plasma exchange within 6 weeks after relapse onset. These patients were classified as GC resistant (initial cohort $n=24$; validation cohort $n=25$ ) [43].

Serum levels of 25D, which represent the body's VD supply, were analyzed by electro-chemiluminescence binding assay (initial cohort: Elecsys ${ }^{\circledR}$, Roche, Basel, Switzerland). For analysis of 25D and 1,25D serum levels in the independent validation cohort, Liason ${ }^{\circledR}$ 25D Total Assay and 1,25D Assay were used (DiaSorin Inc, Stillwater, USA).

For gene expression analyses, $\mathrm{CD}^{+} \mathrm{T}$ cells (from 63 healthy donors and 49 MS patients) were isolated using gradient centrifugation and magnetic cell sorting (Miltenyi Biotec). A WT expression kit (Life technologies, Carlsbad, California, USA) was used to generate and amplify sense strand DNA for fragmentation and labeling using a Gene Chip WT terminal labelling kit (Affymetrix, Santa Clara, California, USA). Samples were hybridized to Affymetrix Human gene 1.0 ST chips (Affymetrix), containing 764,885 distinct oligonucleotide features consolidated into 33,297 probe sets. The Bioconductor Affymetrix package was then used to perform robust multichip average computations. Unwanted variation from the expression data was removed using the remove unwanted variation two-step method.

\section{Animal studies}

Animal studies were approved by the local authorities (Office of Agriculture and Nature Bern, Switzerland; no. BE 101/16; Regional Office for Nature, Environment and Consumer Protection of North Rhine-Westphalia, Germany: no. 84-02.04.2015.A051). Mice were bred under conventional housing conditions at the in-house animal facilities of the University of Bern, the Ruhr University Bochum and the University Medical Center Goettingen. In addition to C57BL/6 and BALB/c wild-type (WT) mice (Janvier Labs, Le Genest-Saint-Isle, France), we also used animals with altered GR signaling: $\mathrm{GR}^{\mathrm{wt}}(\mathrm{Nr} 3 \mathrm{c} 1)$ and $\mathrm{GR}^{\mathrm{dim}}\left(\mathrm{Nr} 3 \mathrm{c}^{\mathrm{tm} 3 \mathrm{GSc}}\right)$ mice on a BALB/c background; $\mathrm{GR}^{\text {flox }}\left(\mathrm{Nr} 3 \mathrm{c} 1^{\mathrm{tm} 2 \mathrm{GSc}}\right)$ and $\mathrm{GR}^{\text {lck }}\left(\mathrm{Nr} 3 \mathrm{c}^{\mathrm{tm} 2 \mathrm{GSc}} \mathrm{Tg}^{\text {(lck-cre) } 1 \mathrm{Cwi}}\right)$ mice on a C57BL/6 background [7, 25]. GR ${ }^{\text {lck }}$ mice do not express the GR specifically in $\mathrm{T}$ cells [7], whereas a point mutation present in $\mathrm{GR}^{\mathrm{dim}}$ mice impairs GR-mediated effects due to impaired dimerization of the receptor in all cell types. Other GR signaling pathways are preserved in $\mathrm{GR}^{\mathrm{dim}}$ mice [37]. C57BL/6 Rheb $^{\text {lck }}$ (mTORc1 KO) has a T cell-specific depletion of mTORc1 activity as described previously [9].

Splenic $\mathrm{CD}^{+} \mathrm{T}$ cells were isolated from $\mathrm{WT}, \mathrm{GR}^{\mathrm{dim}}$ and $\mathrm{Rheb}^{\text {lck }}$ mice by magnetic cell sorting (Pan T cell isolation $\mathrm{kit}^{\circledR}$, Miltenyi Biotec). $1 \times 10^{6} / \mathrm{ml}$ T cells [RPMI media, FCS 10\%, PenStrep 1\%, L-glutamine 1\% (Sigma-Aldrich)] were stimulated with concanavalin A (ConA, 1.5ug/ml, SigmaAldrich) and treated with control (solvent: 0.1\% DMSO), 1,25D (10 $\mathrm{nM}$ and $100 \mathrm{nM})$ and MP (6-600 nM, 24-48 h, $37{ }^{\circ} \mathrm{C}, 5 \% \mathrm{CO}_{2}$ ). The viability of these $\mathrm{T}$ cells was analyzed 
by FACS (annexin V/propidium iodide staining). For the analysis of mTOR inhibition, T cells were treated with different concentrations of 1,25D (10 and $100 \mathrm{nM}$ ) or rapamycin $(547 \mathrm{pM})$ in vitro $(24 \mathrm{~h})$. After lysis (HEPES $50 \mathrm{mM}$, $\mathrm{NaCl} 150 \mathrm{mM}$, glycerol 10\%, EDTA $1 \mathrm{mM}$, Nonidet P-40, $1 \%$ ), western blot was performed to determine mTORc1 activity (Phospho-p70 S6 Kinase (phP70S6K), Cell Signaling Technology, Danvers, USA, 1:500; beta-Actin, SigmaAldrich, 1:15,000). Protein expression is presented as the densitometric ratio of target to housekeeping protein (Image Studio 4.0, LI-COR, Lincoln, USA). To test GR regulation by $1,25 \mathrm{D}$ in regard to mTORc 1 signaling, $\mathrm{T}$ cells from WT and $\mathrm{Rheb}^{\text {lck }}$ mice were treated in vitro for $24 \mathrm{~h}$ with control (solvent: $0.1 \%$ DMSO) or 1,25D (10 nM). GR concentration was measured using a commercial available ELISA (Mouse GR ELISA kit; MyBioSource, San Diego, USA). For EAE experiments WT, GR ${ }^{\text {lck }}$ as well as Rheb ${ }^{\text {lck }}$ on C57B16 background mice were used. Induction of $\mathrm{MOG}_{35-55}$ EAE followed our previously described protocols [45]. Briefly, animals were immunized by a subcutaneous injection of $100 \mu \mathrm{gOG}_{35-55}$ peptide (Institute of Medical Immunology, Charité, Berlin, Germany) in PBS (Thermofischer, Dreieich, Germany) emulsified in complete Freund's adjuvant containing $100 \mu \mathrm{g}$ Mycobacterium tuberculosis H37RA (Difco, Detroit, Michigan, USA), followed by $200 \mathrm{ng}$ pertussis toxin (Quadratech, Epsom, United Kingdom) (i.p., days 0 and 2). Animals were scored daily in a blinded manner using a 10-point EAE scale: 0, normal; 1, reduced tone of tail; 2, limp tail, impaired righting; 3 , absent righting; 4, gait ataxia; 5 , mild paraparesis of hind limbs; 6 , moderate paraparesis; 7 , severe paraparesis or paraplegia; 8 , tetraparesis; 9 , moribund; 10 , death [45]. Treatment was initiated when $\geq 50 \%$ of the animals had an EAE score $\geq 2$.

MP $(0.8 \mathrm{mg} / \mathrm{kg} / \mathrm{day}$ or $4 \mathrm{mg} / \mathrm{kg} /$ day i.p. $), 1,25 \mathrm{D}$ (10 ng/ day, oral gavage), everolimus ( $5 \mathrm{mg} / \mathrm{kg} /$ day, oral gavage), SP600125 (15 mg/kg/day, oral gavage) and controls (solvents for MP: PBS i.p.; for 1,25D/everolimus/SP600125: DMSO in peanut oil p.o., Byodo, Mühldorf am Inn, Germany) were given on three consecutive days. Due to dual drug administration in the combination therapy arm, the control group received two control substances (solvents PBS i.p. and DMSO (in peanut oil p.o.). Further, each monotherapy arm received the control substance of the respective other drug (e.g. MP monotherapy: MP in PBS and DMSO in peanut oil p.o. as $1,25 \mathrm{D} /$ everolimus control substance).

For the analysis of the bioavailability of oral 1,25D used during EAE experiments, we determined peak serum level of 1,25D. For this purpose, 1,25D (10 ng/day) or control (solvent: DMSO in peanut oil) was fed via oral gavage over three consecutive days and blood was collected on day 3, $4 \mathrm{~h}$ after last 1,25D administration. Murine 1,25D serum levels were determined using a chemiluminescence immunoassay (LIAISON $^{\circledR}$, DiaSorin, Stillwater, MN, USA).

\section{Statistical analysis}

All statistical analyses were performed with SPSS ${ }^{\circledR} 20$ (IBM Corporation, Armonk New York, USA). Spearman's Rho was used for correlation analysis. The effect of mTOR/JNK inhibitor or 1,25D on MP-induced T cell apoptosis (human/ murine) and GR protein expression was evaluated by a Wilcoxon signed-rank test. Further, Mann-Whitney test was applied for comparison of murine $1,25 \mathrm{D}$ serum concentrations and ex vivo apoptosis in animals fed with $1,25 \mathrm{D}$ or control. For comparison of categorical data sets, Chi-square test was run. Kruskal-Wallis test adjusted for multiple comparisons using Bonferroni correction was performed for analysis of EAE disease course, 25D serum concentration and gene expression of key regulators of mTORc1 activity. Further, a multivariate logistic regression analysis was used to calculate the risk of a GC-resistant relapse in MS patients with severe $25 \mathrm{D}$ deficiency.

\section{Results}

\section{1,25D increases glucocorticoid-induced apoptosis of human and murine $T$ cells via upregulation of the glucocorticoid receptor}

Given the proposed importance of the expression level of the GR in clinical GC resistance, we first investigated whether 1,25D modifies GR protein levels in human $\mathrm{T}$ cells. As depicted in Fig. 1a, 1,25D (10 and $100 \mathrm{nM}$ ) increased GR expression in a dose-dependent manner in vitro. In line with this observation, GR gene expression in $\mathrm{CD} 8^{+} \mathrm{T}$ cells from a different cohort demonstrated a moderate reduction in individuals with severe 25D deficiency (mean (SE) $\log 2$ GR gene expression: serum 25D level: $<25 \mathrm{nmol} / \mathrm{l}: 9.94$ (0.14), $n=5$ ( $n=2$ healthy controls $/ n=3$ stable MS patients); $\geq 25 \mathrm{nmol} / \mathrm{l}$ : $10.09(0.14), n=107$ ( $n=61$ healthy controls $/ n=46$ stable MS), $p<0.05$, Affymetrix human gene 1.0 ST chip). To address the functional relevance of 1,25D-induced GR upregulation, we employed the GR-dependent model of GCinduced $\mathrm{CD}^{+} \mathrm{T}$ cell apoptosis in vitro. Using a concentration of $75 \mu \mathrm{M}$ methylprednisolone (MP), which is achieved by intravenous pulse therapy during treatment of MS relapses [1], co-incubation with $1,25 \mathrm{D}(10 \mathrm{nM})$ led to a higher apoptosis rate of human $\mathrm{T}$ cells compared to MP alone (Fig. 1b). We next examined whether the synergistic 1,25D/MP effects that we observed in vitro could also be detected in mice ex vivo. For this purpose, C57BL/6 WT mice were fed with 1,25D or control (control: DMSO in peanut oil) on three consecutive days before splenic $\mathrm{T}$ cells were isolated and incubated in vitro for $24 \mathrm{~h}$ with MP. Pre-treatment of animals with 1,25D led to increased GC-induced apoptosis of murine T cells over a broad MP dose range (1.1-1.3-fold, $p<0.01$, Online Resource 1). 



Fig. 1 a GR protein expression normalized to glyceraldehyde 3-phosphate dehydrogenase (GAPDH) after incubation of human $\mathrm{CD}^{+} \mathrm{T}$ cells with $1,25 \mathrm{D}$ in vitro ( $24 \mathrm{~h}$; PHA $0.5 \mu \mathrm{g} / \mathrm{ml} ; n=6$ per group. Cellbased ELISA). Data are expressed as ratio of optical density (OD) $450 \mathrm{GR} / \mathrm{GAPDH}$. b Apoptosis of human $\mathrm{CD}^{+} \mathrm{T}$ cells of healthy donors. Incubation with control (solvent: $0.1 \%$ DMSO), $1,25 \mathrm{D}$, MP or $1,25 \mathrm{D}+\mathrm{MP}$ in vitro (72 $\mathrm{h}$; PHA $0.5 \mu \mathrm{g} / \mathrm{ml} ; n=7$ per group; Annexin V/PI, flow cytometry). Apoptosis of murine splenic-derived $\mathrm{CD}^{+} \mathrm{T}$ cells from $\mathbf{c} \mathrm{BALB} / \mathrm{c} \mathrm{GR}^{\mathrm{wt}}$ (wild type) or $\mathbf{d} \mathrm{BALB} / \mathrm{c} \mathrm{GR}^{\mathrm{dim}}$

To test whether the observed synergistic effect of $1,25 \mathrm{D}$ on GC-induced $\mathrm{T}$ cell apoptosis was mediated via the GR, we utilized rodent cells with a functional impairment of the GR $\left(\mathrm{GR}^{\mathrm{dim}}\right)$. These cells harbor a point mutation that compromises GR dimerization; however, other GR signaling pathways are preserved, which explains residual effects of GCs to induce apoptosis in $\mathrm{GR}^{\mathrm{dim}} \mathrm{T}$ cells [37]. A synergistic effect of $1,25 \mathrm{D}$ and MP on the induction of T cell apoptosis was observed in $\mathrm{T}$ cells with a functional GR (GR ${ }^{\mathrm{wt}}$, Fig. 1c), whereas this effect was not detectable in $\mathrm{GR}^{\mathrm{dim}} \mathrm{T}$ cells (Fig. 1d).
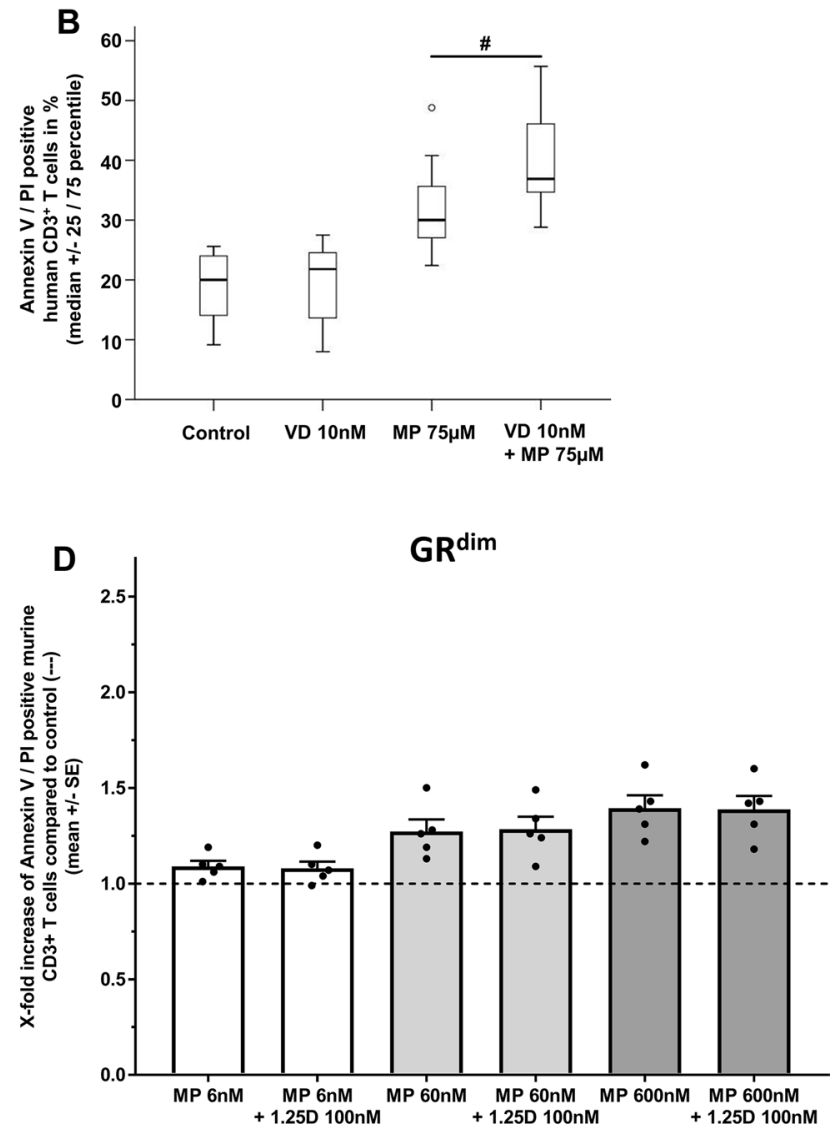

mice. Incubation with control (solvent: $0.1 \%$ DMSO), 1,25D, MP or $1,25 \mathrm{D}+\mathrm{MP}$ in vitro $\left(24 \mathrm{~h}\right.$; ConA $1.5 \mu \mathrm{g} / \mathrm{ml} ; n=9-10\left(\mathrm{GR}^{\mathrm{wt}}\right) ; n=5$ $\left(\mathrm{GR}^{\mathrm{dim}}\right)$; Annexin V/PI, flow cytometry). Apoptosis is depicted as increase over control (-; control: solvent $0.1 \%$ DMSO). In the control groups of each genotype, mean percentage of apoptotic murine $\mathrm{T}$ cells (SE) was as follows: BALB/c GR ${ }^{\mathrm{wt}} 46.1 \%$ (4.3) vs BALB/c $\mathrm{GR}^{\mathrm{dim}} 42.3 \%$ (3.6). GR glucocorticoid receptor, $O D$ optical density, $1,25 D 1,25(\mathrm{OH})_{2} \mathrm{D}_{3}, M P$ methylprednisolone, $S E$ standard error. Statistics: Wilcoxon signed-rank test: $\#<0.05$

\section{1,25D augments therapeutic efficacy of methylprednisolone in $\mathrm{MOG}_{35-55}$ experimental autoimmune encephalomyelitis in a glucocorticoid receptor-dependent manner}

To determine the bioavailability of our therapeutic oral $1,25 \mathrm{D}$ dose regime in mice, serum levels of $1,25 \mathrm{D}$ were tested $4 \mathrm{~h}$ after last 1,25D application. After oral gavage, serum 1,25D levels increased 6.1-fold in mice treated on three consecutive days with $10 \mathrm{ng} 1,25 \mathrm{D}$ compared to control 



Fig. 2 a Murine 1,25D serum concentration after 3 days of oral gavage with 1,25D $10 \mathrm{ng} /$ day or control (solvent: DMSO in peanut oil). Cardiac blood was sampled $4 \mathrm{~h}$ after the last oral gavage $(n=5$ per group, chemiluminescence immunoassay). Clinical disease course of $\mathrm{MOG}_{35-55}$ EAE in C57BL/6 wild-type mice $\mathbf{b}$, $\mathbf{c}$ or $\mathrm{GR}^{\text {lck }}$ mice devoid of the T cell GR $\mathbf{d}$ treated for three consecutive days with control (DMSO in peanut oil), 1,25D (10 ng/day), MP [b intermediate MP dosage $(0.8 \mathrm{mg} / \mathrm{kg} /$ day $), \mathbf{c}, \mathbf{d}$ high MP dosage $(4.0 \mathrm{mg} / \mathrm{kg} /$ day $)$ ]

treatment (control: DMSO in peanut oil; Fig. 2a). For EAE experiments, we attempted to mimic GC pulse therapy of MS by treating the mice for three consecutive days starting at the onset of moderate signs of EAE. Mice first received doses of both substances (MP $0.8 \mathrm{mg} / \mathrm{kg} ; 1,25 \mathrm{D} 10 \mathrm{ng}$ ) that had previously been demonstrated to only moderately improve symptoms of EAE $[4,53]$. Whereas monotherapy with MP at this suboptimal dose did not lead to significant changes of clinical scores, 1,25D monotherapy resulted in mild clinical improvement compared to control treatment
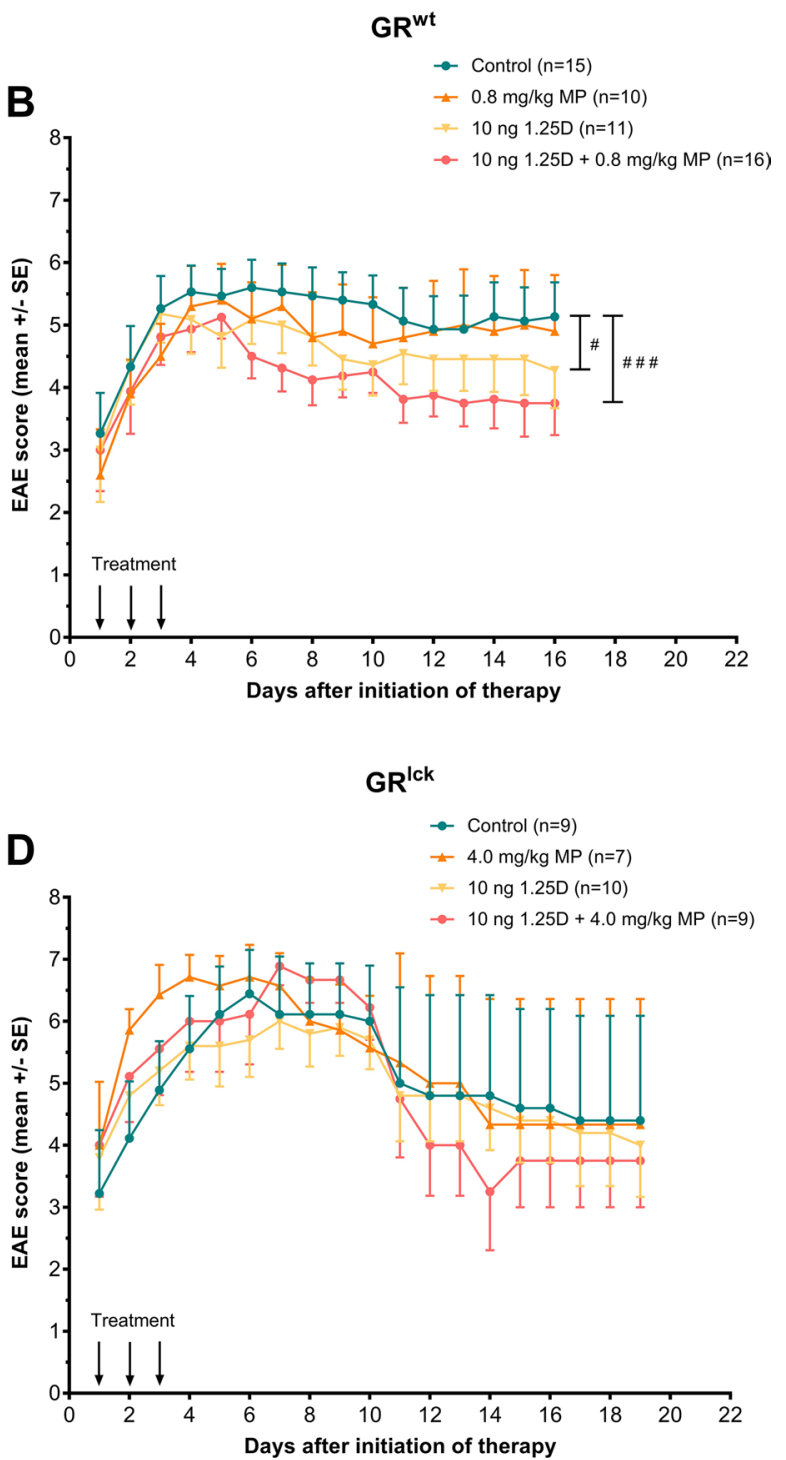

or $1,25 \mathrm{D}+\mathrm{MP}$. Downwards arrow: days of treatment. EAE score: 10 -score system according to Ref. [45]. Numbers of included animals are given in the figure. EAE experimental autoimmune encephalomyelitis, $G R^{l c k}$ mice with glucocorticoid receptor deficient T cells, $G R^{w t}$ glucocorticoid receptor wild type, $M P$ methylprednisolone, $S E$ standard error, $1,25 D \quad 1,25(\mathrm{OH})_{2} \mathrm{D}_{3}$. Statistics: a Mann-Whitney test: $\# \#<0.01$, b-d Kruskal-Wallis test: \#<0.05; \#\#\# $\leq 0.001$

(control: PBS i.p. + DMSO in peanut oil p.o.; improvement of mean cumulative EAE score by $10.6 \% ; p<0.05$, Fig. $2 b$ ). In contrast, strongest clinical effects were observed for the combination of 1,25D and MP (compared to control treatment reduction of mean cumulative EAE score by $19.1 \%$, $p<0.001$, Fig. $2 b$ ). To more closely resemble the situation in patients during MS relapse therapy, a higher GC dose (MP $4 \mathrm{mg} / \mathrm{kg}$ [37]) was used (Fig. 2c). Here, compared to control treatment (PBS i.p.+ DMSO in peanut oil p.o.) respective monotherapies reduced the mean cumulative EAE score by 
14.1\% (MP $4 \mathrm{mg} / \mathrm{kg})$ and 18.3\% (1,25D $10 \mathrm{ng} /$ day; each $p<0.001)$. Again, the strongest effect was observed for the MP/1,25D combination therapy, which ameliorated EAE disease score by $35.5 \%$ ( $p<0.001$; Fig. $2 c$ ). We next examined whether the synergistic effect of the 1,25D and MP combination therapy was dependent on the GR. In mice that are devoid of the GR in T cells (GR $\left.{ }^{\text {lck}}\right)$, this therapeutic combination regime did not lead to any clinical effects (Fig. 2d).

\section{D levels are reduced in MS patients with glucocorticoid-resistant relapses and $\mathrm{T}$ cell apoptosis is exclusively augmented by 1,25D in MS patients with glucocorticoid-resistant MS relapses}

To address the potential relevance of our findings concerning the $1,25 \mathrm{D} / \mathrm{GC}$ synergism in patients, we investigated 25D serum concentrations in patients with stable MS in comparison with patients with GC-responsive and GCresistant MS relapses. Patient populations did not differ in gender or MS disease duration (Online Resource 2, initial cohort). Although GC-resistant patients were younger than those with GC-responsive MS relapses, age was not associated with 25D serum levels ( $\rho-0.076, p>0.05, n=110)$. Baseline disability before relapse did not differ between groups (Online Resource 2). During relapse and before steroid administration, EDSS was higher in patients with GC-resistant compared to GC-responsive relapse. Although patients with GC-responsive relapse received approximately $3400 \mathrm{mg}$ less methylprednisolone, only in these patients an EDSS improvement was observed. In contrast, patients with GC-resistant relapse even tended to further deteriorate despite high-dose GC treatment (Online Resource 2). In addition to the extent of improvement, patients with GC response also tended to improve more quickly after 0.5 (SD 0.6) months, whereas EDSS analysis in GC-resistant patients was performed after 0.7 (0.6) months (Online Resource 2). In GC-resistant patients with the longest interval between EDSS assessments post-relapse EDSS $\geq 1.5$ months after first EDSS; $n=3)$ a prominent EDSS deterioration $(+2.7$ (2.3) was observed, arguing against delayed effects of GC.

Patients with GC-resistant relapse had polysymptomatic relapses with on average 0.4 more clinical symptoms than those who responded well to GC treatment. However, when analyzing distribution of relapse symptoms we did not observe specific patterns in patients with GC-resistant or GC-responsive relapse (e.g. optic neuritis vs. myelitis; Online Resource 3). Furthermore, patients with GC-resistant relapse exhibited on average 1.2 more gadoliniumenhancing lesions compared to those with GC-responsive relapse (Online Resource 2). Since GC-resistant patients had received higher GC dosages for relapse therapy, we investigated whether the GC dose influences 25D serum concentrations before and after GC treatment in a different subset of patients [median GC dosage $1665 \mathrm{mg}$ (IQR 1525), min $750, \max 7000, n=10]$. Here, no differences in $25 \mathrm{D}$ serum levels were observed before and after GC administration [median (IQR) 25D serum levels (nmol/l) prior to GC therapy: 7.2 (15.2) versus post GC pulse therapy: 10.0 (12.1), $p>0.05]$. Overall, 25D serum levels in the initial cohort were almost 50\% lower in MS patients with relapses than in stable patients [MS with relapses median (IQR): $27.6 \mathrm{nmol} / 1$ (25.7); stable MS without relapses $48.8 \mathrm{nmol} / 1$ (36.9); $p<0.01]$. This difference was mainly due to the subgroup of patients with GC-resistant relapses. In these patients, 25D serum levels [21.9 (21.3) nmol/l] were 21\% lower compared to GC-responsive MS $(p<0.05)$ and 55\% lower compared to stable MS ( $p \leq 0.001$; Fig. 3a). A classification of 25D serum levels into established categories $(<25 \mathrm{nmol} / \mathrm{l}$ : severe deficiency; $25-49.9 \mathrm{nmol} / \mathrm{l}$ : deficiency; $\geq 50 \mathrm{nmol} / \mathrm{l}$ : sufficient 25D supply [18, 21]) demonstrated that $66.7 \%$ of GCresistant MS patients were severely 25D deficient in contrast to only $26.7 \%$ of GC-responsive and $21.4 \%$ of stable MS patients. The influence of 25D serum concentration on GC efficacy was further validated using a multivariate logistic regression analysis adjusted for age, gender, MS disease duration, and presence of disease-modifying MS treatment. MS patients who experienced an acute relapse $(n=54)$ but did not exhibit severe 25D deficiency had a considerably higher likelihood of responding to GC pulse therapy than patients with severe 25D deficiency (odds ratio 10.6; 95\% confidence interval 2.2-51.5, $p<0.05$ ). Findings of reduced 25D serum concentrations in GC-resistant patients were validated using an independent cohort of RMS patients (validation cohort, $n=85$, see Online Resource 4 for baseline characteristics). Also in this cohort, GC-resistant patients $(n=25)$ had lower 25D levels than stable $(n=40)$ and GCresponsive MS patients ( $n=20$, Fig. 3b). 1,25D values in this validation cohort did not demonstrate a correlation with 25D serum levels or a different distribution within the three MS patient groups (Online Resource 5). We next addressed whether the biologically active form of $25 \mathrm{D}, 1,25 \mathrm{D}$, differentially affects GC-induced T cell apoptosis in GC-responsive $(n=8)$ and GC-resistant $(n=5)$ MS patients during relapse. Patients did not differ in gender, age, disease duration or the presence of immunotherapy (Online Resource 6). GC-resistant MS patients had received 2.7-fold higher dosage of GCs during GC pulse therapy $(p<0.05)$. Despite higher GC dosages, baseline apoptosis after GC therapy tended to be lower in these patients compared to patients with GC-responsive relapse (Fig. 4, $p>0.05$ ). In GC-responsive MS patients, the addition of $1,25 \mathrm{D}(10 \mathrm{nM})$ did not lead to an additional effect of MP-induced T cell apoptosis in vitro (Fig. 4a). In contrast, 1,25D led to an increase of MP-induced apoptosis in T cells from GC-resistant MS patients (Fig. $4 \mathrm{~b}, p<0.05$ ). 


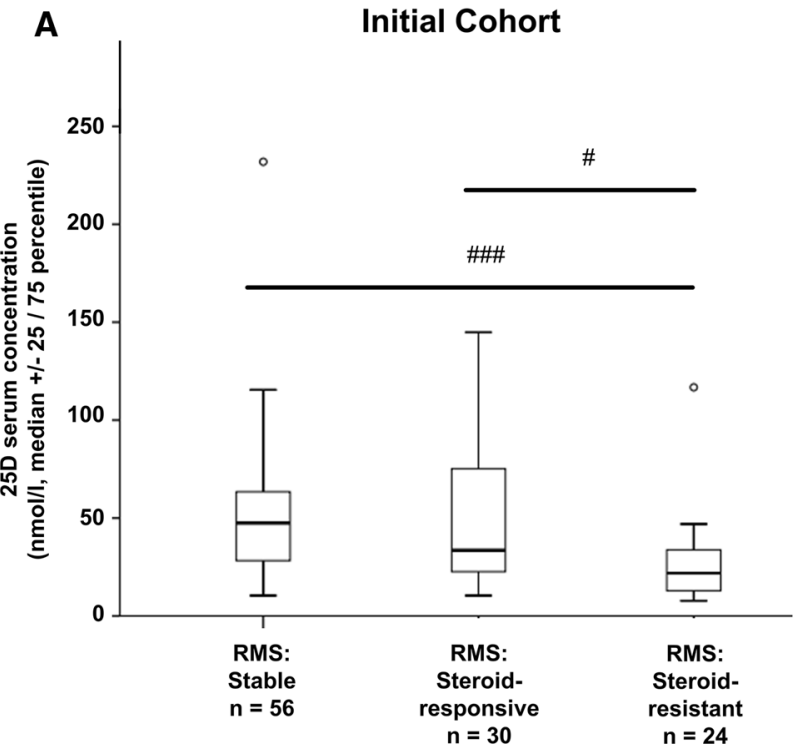

Fig. 3 25D serum concentrations in $\mathrm{nmol} / \mathrm{L}$ of patients with relapsing multiple sclerosis (RMS) in the initial cohort (a) and the validation cohort (b). Blood sampling was performed during stable disease (initial cohort: $n=56$, validation cohort: $n=40$ ), glucocorticoid-respon-

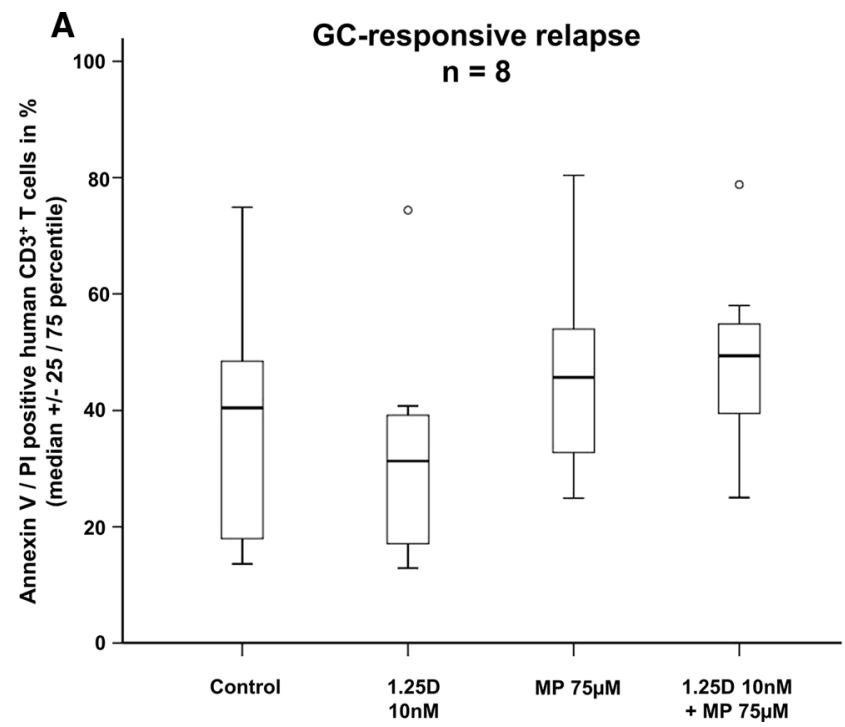

Fig. 4 a Apoptosis of $\mathrm{CD}^{+} \mathrm{T}$ cells of MS patients during glucocorticoid-responsive relapse $(n=8)$ or $\mathbf{b}$ glucocorticoid-resistant relapse $(n=5)$. Incubation with control (solvent: $0.1 \%$ DMSO), 1,25D, MP or $1,25 \mathrm{D}+\mathrm{MP}$ in vitro for $72 \mathrm{~h}$ (PHA $0.5 \mu \mathrm{g} / \mathrm{ml}$; Annexin V/PI, flow

To address if rather $\mathrm{CD} 4^{+}$or $\mathrm{CD} 8^{+} \mathrm{T}$ cells are involved, we investigated GR as well as HSP90-protein expression in blood-derived T cells from a limited group of RMS patients with GC-responsive and GC-resistant relapse by western blot. Here, a differential regulation of $\mathrm{GR}$ in $\mathrm{CD} 8^{+} \mathrm{T}$ cells was observed. Further a trend towards a GR regulation in $\mathrm{CD} 4^{+} \mathrm{T}$ cells as well as an increase in the HSP90/GR ratio

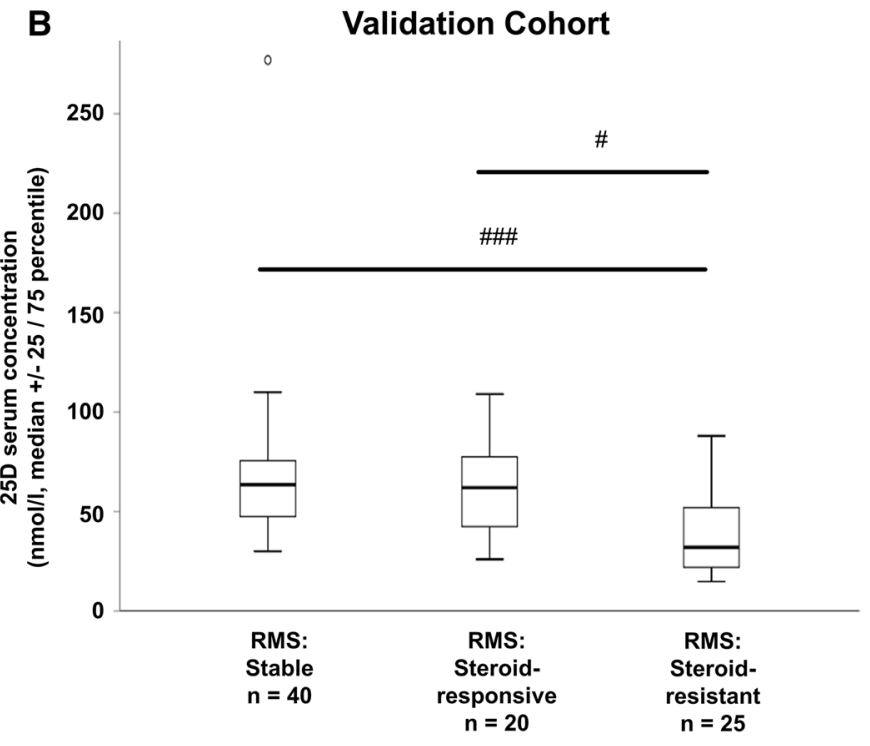

sive relapse (validation cohort: $n=30$, validation cohort: $n=20$ ) or glucocorticoid-resistant relapse (initial cohort: $n=24$, validation cohort: $n=25$ ). $25 D 25$-hydroxyvitamin D. Statistics: Kruskal-Wallis test: \#<0.05, \#\#\# $\leq 0.001$

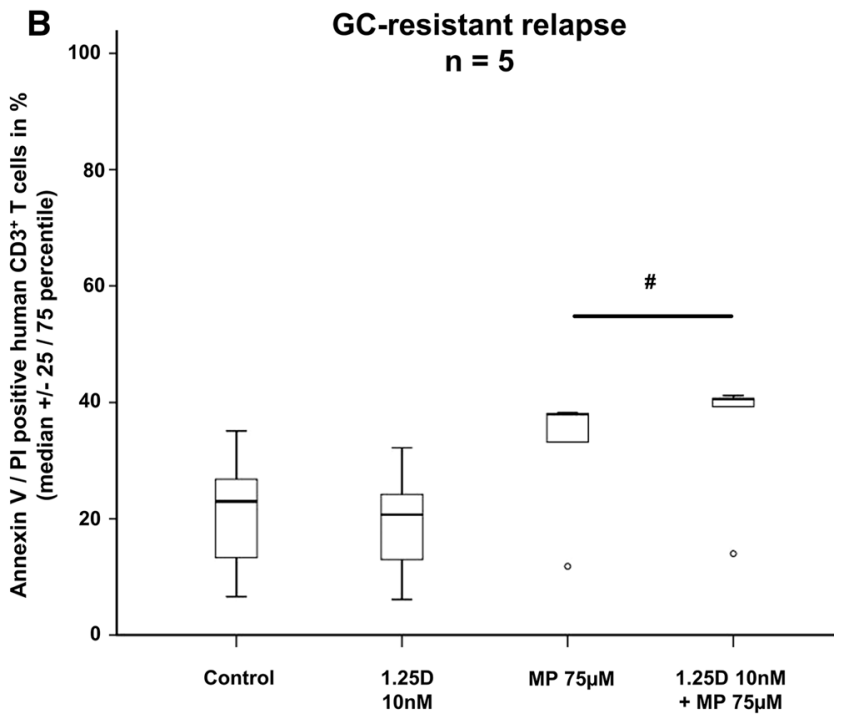

cytometry). GR glucocorticoid receptor, $M P$ methylprednisolone, $R M S$ relapsing multiple sclerosis, $25 D 25$-hydroxyvitamin $\mathrm{D}, 1,25 D$ $1,25(\mathrm{OH})_{2} \mathrm{D}_{3}$. Statistics: Wilcoxon signed-rank test: \#<0.05

in both $\mathrm{T}$ cell subsets was found (Online Resources 7, 8). In addition, active demyelinating MS lesions in brain biopsies of three patients (one with GC-resistant and two with GC-responsive relapse) were investigated to evaluate $\mathrm{GR}^{+} \mathrm{T}$ cells in situ. Here, a pronounced infiltration of $\mathrm{CD}^{+}$as well as $\mathrm{CD} 4^{+}$and $\mathrm{CD} 8^{+} \mathrm{T}$ cells was present in the two patients with GC-responsive relapse compared to the single patient 
with GC-resistant relapse (Online Resources 9, 10). However, in this limited number of samples, no differences in GR expression were observed between phenotypes and between T cell subsets.

\section{Synergistic effects of 1,25D and glucocorticoids are mediated by inhibition of mTORc1 signaling}

We next addressed if mTOR or JNK signaling pathways, both implicated in the regulation of GR expression, are also involved in the observed 1,25D/GC synergism. In murine
T cells, 1,25D reduced protein expression of the mTORc1 downstream target phP70S6 K in a dose-dependent manner, proving the inhibition of mTORc1 activity (Fig. 5a). Likewise, gene expression of a key regulator of mTORc1 activity in human $\mathrm{CD}^{+} \mathrm{T}$ cells from a large cohort (Online Resource 11) was associated with 25D serum levels. Thus, expression of tuberous sclerosis complex (TSC)-1 was reduced in individuals with severe 25D deficiency $(<25 \mathrm{nmol} / 1 ; n=5(n=2$ healthy controls $/ n=3$ stable MS patients)) compared to individuals with $25 \mathrm{D}$ levels between $25-49.9 \mathrm{nmol} / \mathrm{l}$ (deficient; $n=42(n=24$ healthy controls $/ n=18$ stable MS patients $))$
A

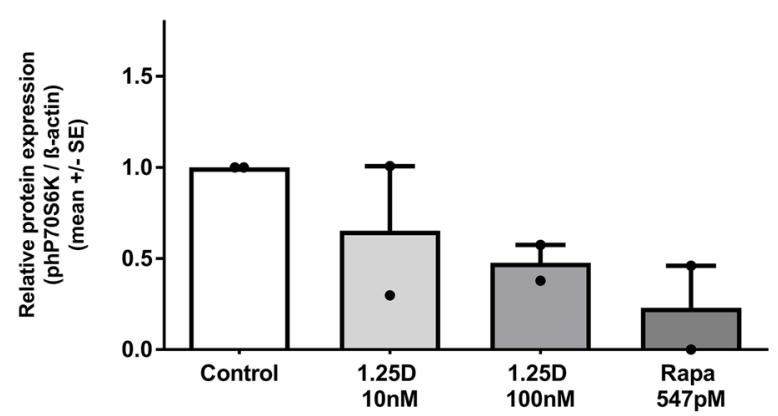

C

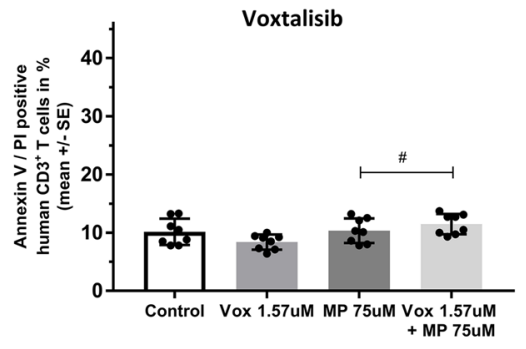

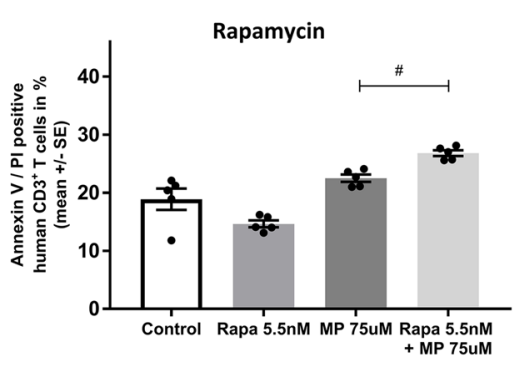



MP 750

\section{B}

D

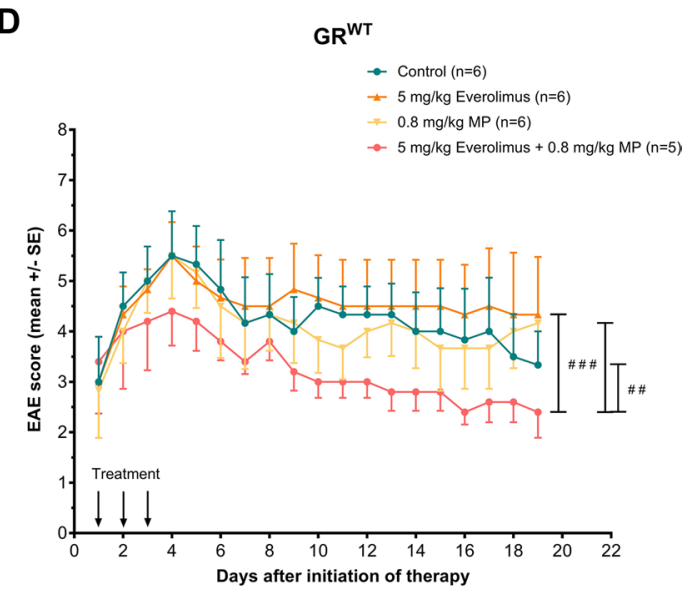



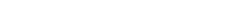

Fig. 5 a Protein expression of phospho-P70 S6 Kinase (phP70S6K, downstream target of mTORc1) normalized to $\beta$-actin expression. Murine $\mathrm{CD}^{+} \mathrm{T}$ cells were incubated with control (solvent: $0.1 \%$ DMSO), $1,25 \mathrm{D}$ or rapamycin in vitro ( $24 \mathrm{~h}$; ConA $1.5 \mu \mathrm{g} /$ $\mathrm{ml} ; n=2$ independent experiments, densitometry of western blots). b $\log 2$ expression of TSC- 1 gene in human $\mathrm{CD}^{+} \mathrm{T}$ cells in association with $25 \mathrm{D}$ serum concentrations $(<25 \mathrm{nmol} / \mathrm{l} ; n=5 \quad(n=2$ healthy controls $/ n=3$ stable MS patients); $25-49.9 \mathrm{nmol} / \mathrm{l} ; n=42$ ( $n=24$ healthy controls $/ n=18$ stable MS patients); $\geq 50 \mathrm{nmol} / \mathrm{l}$; $n=65$ ( $n=37$ healthy controls $/ n=28$ stable MS patients); see Online Resource 11; Affymetrix Human gene 1.0ST chip). c Apoptosis of human $\mathrm{CD}^{+} \mathrm{T}$ cells of healthy donors. Incubation with control (solvent: $0.1 \%$ DMSO), methylprednisolone and different mTOR inhibi- tors: voxtalisib ( $n=4$ in duplicates;) rapamycin $(n=5)$ and everolimus ( $n=6$ in duplicates) in vitro ( $24 \mathrm{~h}$; PHA $0.5 \mu \mathrm{g} / \mathrm{ml}$, Annexin V/ PI, flow cytometry). d Disease course of $\mathrm{MOG}_{35-55} \mathrm{EAE}$ in C57BL/6 wild type treated with control (solvent: DMSO in peanut oil), everolimus $(5 \mathrm{mg} / \mathrm{kg} /$ day $)$, MP $(0.8 \mathrm{mg} / \mathrm{kg} /$ day $)$ or everolimus + MP. Downwards arrow: days of treatment. EAE score: 10-score system according to Ref. [45]. Numbers of included animals are given in the figure. $M S$ multiple sclerosis, $M P$ methylprednisolone, $G R$ glucocorticoid receptor, phP70S6K phospho-p70 S6 kinase, Rapa rapamycin, $S E$ standard error, TSC-1 tuberous sclerosis complex 1, 25D 25-hydroxyvitamin $\mathrm{D}, 1,25 \mathrm{D} 1,25(\mathrm{OH})_{2} \mathrm{D}_{3}$; Vox voxtalisib, Statistics: b, d Kruskal-Wallis test: \#<0.05; \#\# $\leq 0.01$; $\mathbf{c}$ Wilcoxon signed-rank test: $\#<0.05 ; \# \# 0.01$ 
or with sufficient levels ( $\geq 50 \mathrm{nmol} / \mathrm{l} ; n=65$ ( $n=37$ healthy controls $/ n=28$ stable MS patients); Fig. 5b). No associations between 25D serum levels and Akt, TSC-2 or Rheb gene expression were observed (data not shown). We next demonstrated that three different types of mTOR inhibitors increased GC-induced apoptosis in human T cells (Fig. 5c), indicating a class-specific effect. In contrast, GC co-incubation with SP600125, a pharmacological JNK inhibitor [5], did not alter GC-induced human T cell apoptosis (Online Resource 12A) and had no therapeutic effect on GC treatment efficacy in EAE (Online Resource 12B).

To further investigate the relevance of the mTORc1 pathway for 1,25D/GC synergism, we used murine T cells deficient in mTORc1 signaling (Rheb ${ }^{\text {lck }}$ ). In these cells, $1,25 \mathrm{D}$ failed to upregulate GR and to increase GC-induced apoptosis (Fig. 6a, b). Further, in EAE, combined 1,25D/ GC treatment in Rheb ${ }^{\text {lck }}$ mice worsened clinical disease course in comparison with control treatment (control: PBS i.p. + DMSO in peanut oil p.o.; Fig. 6c). We next assessed the impact of pharmacological mTORc1 inhibition on EAE using everolimus, a rapalog, which allosterically and specifically blocks mTORc1 activity [10]. Everolimus was administered in a dose $(5 \mathrm{mg} / \mathrm{kg}$, p.o.) that was demonstrated to result in a strong mTORc1 inhibition in vivo [11]. Whereas respective monotherapies did not have any relevant effect on clinical EAE disease course compared to control treatment (control: PBS i.p. + DMSO in peanut oil p.o.), the combination therapy with everolimus and MP led to a decrease of EAE disease severity by $23.5 \%$ compared to control (Fig. 5d, $p<0.01$ ).

\section{Discussion}

Given the central role of the GR in mediating clinical GC resistance [38], we investigated if VD augments GC efficacy via modulation of GR expression [39].

We found that 1,25D increased GR protein levels and enhanced GC responsiveness in vitro and in vivo. Synergistic efficacy of the $1,25 \mathrm{D} / \mathrm{GC}$ combination therapy was dependent on the GR in T cells as demonstrated using two different mouse models with reduced or absent GR signaling.
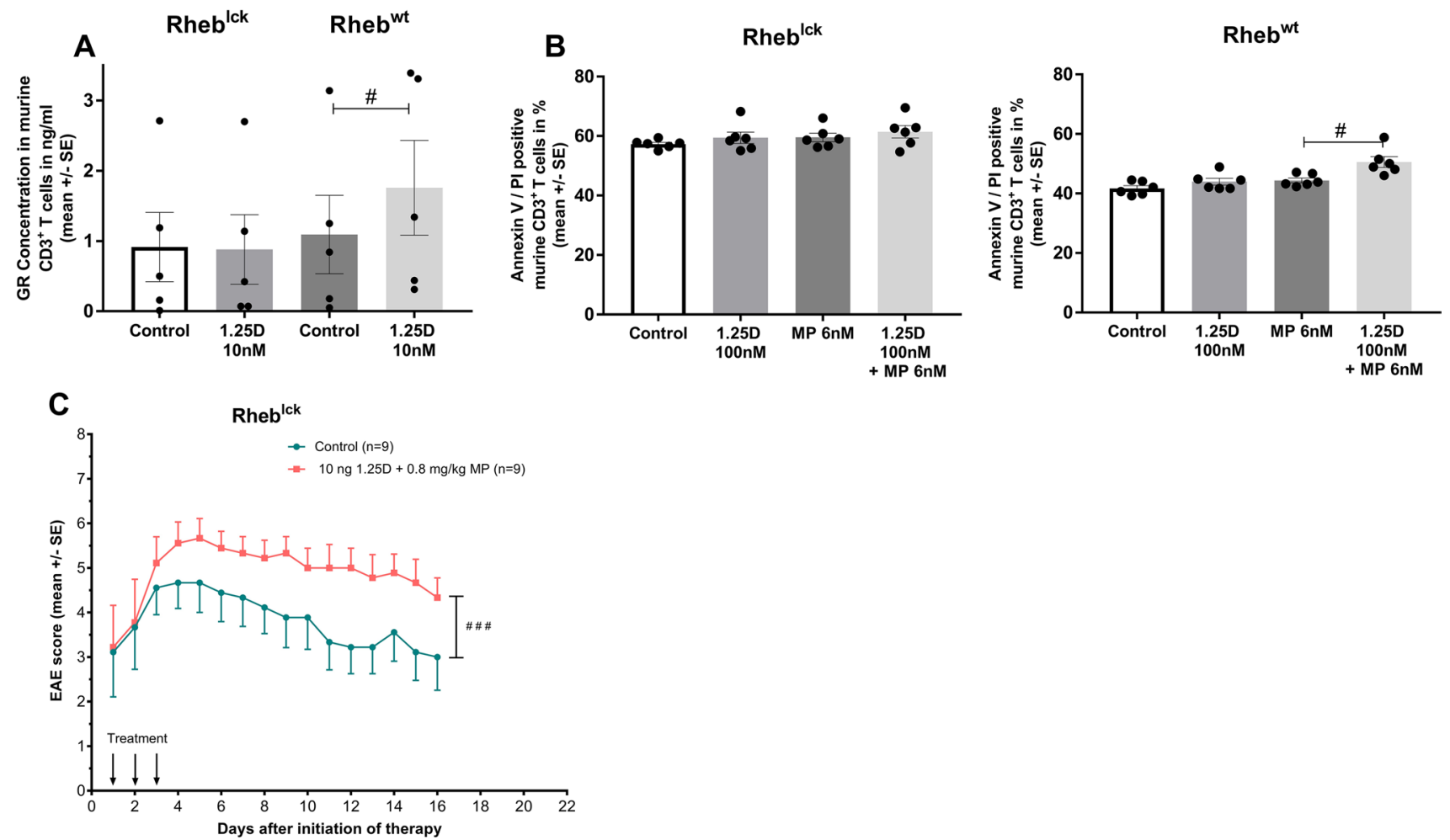

Fig. 6 a GR protein concentration in $\mathrm{ng} / \mathrm{ml}$ after incubation of murine $\mathrm{CD}^{+}{ }^{+} \mathrm{T}$ cells (Rheb ${ }^{\text {lck }}$ vs. Rheb ${ }^{\mathrm{wt}}$ ) with $1,25 \mathrm{D}$ in vitro ( $24 \mathrm{~h}$; ConA $1.5 \mu \mathrm{g} / \mathrm{ml}, n=5$; ELISA). b Apoptosis of murine splenic-derived $\mathrm{CD}^{+} \mathrm{T}$ cells from $\mathrm{C} 57 \mathrm{BL} / 6 \mathrm{Rheb}^{\mathrm{wt}}$ or $\mathrm{Rheb}^{\text {lck }}$ mice. Incubation with control (solvent: $0.1 \%$ DMSO), 1,25D $100 \mathrm{nM}$, MP $6 \mathrm{nM}$ or $1,25 \mathrm{D}+\mathrm{MP}$ in vitro $(24 \mathrm{~h}$; ConA $1.5 \mu \mathrm{g} / \mathrm{ml} ; n=3$ in duplicates; Annexin V/PI, flow cytometry). c Disease course of $\mathrm{MOG}_{35-55}$ EAE in $\mathrm{Rheb}^{\mathrm{lck}}$ treated for three consecutive days with control (solvent:
DMSO in peanut oil) or $1,25 \mathrm{D}(10 \mathrm{ng} /$ day $)+\mathrm{MP}(0.8 \mathrm{mg} / \mathrm{kg} /$ day $)$. Downwards arrow: days of treatment. EAE score: 10-score system according to Ref. [45]. Numbers of included animals are given in the figure. $G R$ glucocorticosteroid receptor, $M P$ methylprednisolone, Rheb ras homolog enriched in brain, $S E$ standard error, $1,25 D$ $1,25(\mathrm{OH})_{2} \mathrm{D}_{3}, 95 \%$ CI 95\% confidence interval. Statistics: a, b Wilcoxon signed-rank test: \#<0.05; c, $\mathbf{d}$ Kruskal-Wallis test: \#\# $\leq 0.01$, $\# \#$ \# 0.001 
Low 25D serum levels were associated with decreased GR mRNA expression in human T cells and MS patients with profound 25D deficiency were more likely to exhibit clinical resistance to GCs during relapse. Likewise, 1,25D increased GC effects in vitro only in T cells from GC-resistant MS patients. Several findings point to a crucial role of mTORc1 signaling in mediating $1,25 \mathrm{D} / \mathrm{GC}$ functional synergism. Severe 25D deficiency was associated with a downregulation of an archetype mTORc1 inhibitor in human T cells. In animals with $\mathrm{T}$ cell-specific depletion of mTORc1, the synergistic 1,25D/GC effects on GR upregulation, T cell apoptosis and therapeutic efficacy in EAE were abolished. Finally, treatment with a specific mTORc1 inhibitor also augmented therapeutic GC efficacy in EAE.

An association of hypovitaminosis D (25D-deficiency) and increased use of steroids was described for other inflammatory diseases such as asthma and inflammatory bowel disease [20, 47], and different effector cells and mechanisms have been implied in mediating this effect. In EAE, $\mathrm{T}$ cells appear to be pivotal in mediating synergistic effects of 1,25D and GC, since T cell-specific deletion of either GR or mTORc1 abrogated these effects. This fits well with previous data demonstrating lack of efficacy of GC monotherapy in EAE only when the GR is deleted in T cells, but not in monocytes, macrophages and microglia [54]. Upregulation of the GR has been associated with a better prognosis and increased clinical efficacy of GC treatment in several immune-mediated and malignant diseases [28, 50]. It is noteworthy that the GR can either regulate gene transcription through binding to GC-responsive elements (GRE) presented in regulatory DNA regions, or by interacting with transcription factors such as nuclear factor kappa B or activator protein-1 [16]. In $\mathrm{GR}^{\mathrm{dim}}$ mice, dimerization of the GR and thus its ability to bind to GREs are strongly impaired. As a consequence, regulation of at least a subset of genes by the GR is abolished [37]. The lack of any 1,25D/GC synergism in $\mathrm{GR}^{\mathrm{dim}}$ cells, therefore, argues that altered gene expression is relevant for the observed effects being in line with the finding of increased GR binding to a GRE after preincubation with VD [57]. We demonstrated clear synergism of $1,25 \mathrm{D}$ with MP as the evidence-based GC for the treatment of acute MS relapse. As the synergism is mediated via an upregulation of the GR, it appears likely that this effect is not specific for MP and might be used to increase efficacy of other GCs, e.g. dexamethasone. In vitro, VD/dexamethasone combination suppresses the activation of synovial fibroblasts via modulation of $\mathrm{CCR}^{+}$T-helper memory cells [8]. We did not observe any clinical effect of 1,25D monotherapy in mice with a $\mathrm{T}$ cell-specific GR-deficiency, in contrast to robust efficacy in WT mice, in line with the well-known VD effects on $\mathrm{MOG}_{35-55}$ EAE [7, 56]. Since the VD receptor and GR are located on different chromosomes (VDR: 12q13.11; GR: 5q31.3 [32]), a coincidental knock-out of both receptors by the Cre recombinase expressed in $\mathrm{GR}^{\text {lck }} \mathrm{T}$ cells appears unlikely. Therefore, we speculate that the GR might also be relevant for specific immunological effects of VD, a hypothesis that warrants further investigation.

For the analysis of systemic VD supply in our MS patient cohorts, the major circulating metabolite (25D) was used because it has a longer half-life than bioactive 1,25D and is less influenced by hormones or medications [24]. Reduced 25D serum levels in patients with GC-resistant relapse compared to stable patients and patients with GC-responsive relapse were observed in two independent cohorts of RMS patients. Lack of correlation of $1,25 \mathrm{D}$ with $25 \mathrm{D}$ serum levels points to higher sensitivity of 25D serum levels, since $1,25 \mathrm{D}$ serum concentration is kept in the normal range even if $25 \mathrm{D}$ concentration is reduced [24]. In addition, systemic $1,25 \mathrm{D}$ serum levels will not properly reflect local bioactive $1,25 \mathrm{D}$, since $\mathrm{T}$ cells and macrophages also have the ability to directly convert $25 \mathrm{D}$ into $1,25 \mathrm{D}$ at the site of action, which cannot be detected by analyzing serum samples [36]. Together, these factors argue for the use of 25D serum concentration as a global measure of the body's VD supply as is performed in most epidemiological and interventional studies $[3,35]$.

In our multivariate analysis, corrected for various potential confounders (age, gender, MS disease duration, presence of disease-modifying MS treatment), severe 25D deficiency was associated with clinical GC resistance even after GC dose escalation. The clinical definition of GC resistance followed current national guidelines on the use of plasma exchange as evidence-based treatment intensification for MS relapses [13]. The retrospective data analysis in our patient cohorts is a clear limitation. Although we did not observe major clinical or epidemiological characteristics between the GC-responsive and -resistant patients that confounded our findings to a large extent, these cannot completely be excluded. Especially, masking of delayed GC effects due to early initiation of plasma exchange as intensified relapse treatment according to national guidelines cannot completely be ruled out [13]. However, in a more recent prospective double-blinded study, an EDSS improvement already after 28 days was demonstrated which did not further change after 180 days [22]. In addition, severely reduced 25D levels in GC-resistant patients in two independent cohorts also argue for robustness of our findings.

Also, our experimental data on the synergistic effect of $1,25 \mathrm{D}$ on GC-induced apoptosis exclusively in T cells from GC-resistant patients argue for a true biological difference between the cohorts.

In patients with GC-resistant relapse, basal T cell apoptosis ex vivo was lower compared to steroid-responsive MS patients despite application of twofold higher GC dosages in steroid-resistant patients. This observation is in line with previous data demonstrating lower suppressive capacity of 
dexamethasone on $\mathrm{T}$ cell proliferation in GC-resistant than in GC-responsive patients [29]. Peripheral $\mathrm{CD}^{+} \mathrm{T}$ cells from a limited number of patients with GC-resistant relapse had a higher GR protein expression in comparison with cells from patients with GC-responsive relapse, similar to previous findings in peripheral mononuclear cells [29]. In early active demyelinating CNS lesions, in one investigated GCresistant patient there were less $\mathrm{T}$ cells, albeit the expression of the GR did not appear to differ between patients with and without GC response. These preliminary findings will have to be followed up also with respect to the presumed site of action of GC.

Concerning the signaling mechanism for $1,25 \mathrm{D} / \mathrm{GC}$ synergism, we identified a role of the mTORc1 but not the JNK pathway downstream of VD. Both genetic deletion and pharmacological inhibition point to mTORc1 inhibition as major mechanism mediating 1,25D/GC synergism. In individuals with severe 25D-deficiency TSC-1 gene expression was reduced. Since TSC-1 is an archetype mTORc1 inhibitor [19], downregulation of TSC-1 would result in a disinhibition of the mTORc1 pathway. Furthermore, our in vitro data indicated a functional inhibition of mTORc1 enzyme activity by $1,25 \mathrm{D}$ in $\mathrm{T}$ cells, with inhibition of phosphorylation of a downstream target of mTORc1.

In vitro, $\mathrm{T}$ cells from Rheb ${ }^{\text {lck }}$ mice have a $\mathrm{T}$ cell-specific depletion of mTORc1 activity [9]. In Rheb-deficient T cells, 1,25D did not lead to GR upregulation and these mice did not exhibit synergistic 1,25D/GC effects in apoptosis induction. Moreover, EAE data in Rheb ${ }^{\text {lck }}$ animals also supported our conclusion, as we did not find any inhibitory effect on the disease by the $1,25 \mathrm{D} / \mathrm{GC}$ combination. Similar to findings reported before also in our hands active $\mathrm{MOG}_{35-55} \mathrm{EAE}$ resulted in a more cerebellar phenotype, which is presumably associated with a more pronounced $\mathrm{Th} 2$ rather than Th1/Th17 CNS autoimmunity [9]. VD and GCs drive Th2 polarization $[12,48]$, which could hypothetically explain the exacerbated disease course of $\mathrm{MOG}_{35-55}$ EAE in Rheb ${ }^{\text {lck }}$ mice treated with the combination of 1,25D/GC. Finally, synergistic effects of everolimus and GC in WT EAE mice point to mTORc1-inhibition as major mechanism responsible for the increased GC efficacy. Everolimus, a derivative of rapamycin, is a potent mTORc1 inhibitor and approved for the treatment of tuberous sclerosis [49]. Thus, rapid translation into the clinical setting of MS relapse treatment appears feasible, especially since its usage would be temporally restricted, potentially reducing possible adverse drug reactions (e.g. infections and ulcera).

Despite highly efficacious disease-modifying therapies, GCs remain the most commonly used substances in MS treatment $[17,40]$. Nevertheless, approximately $30 \%$ of MS patients report insufficient remission and 50\% suffer from steroid-related side effects [33]. The use of plasma exchange/ immune adsorption as treatment intensification during acute relapse constitutes an invasive procedure. Thus, further translation of alternative approaches to improve treatment of acute neuroinflammation would meet a high clinical need. However, given the high heterogeneity of relapse phenotypes and dynamics, clinical studies face several hurdles, e.g. sample size and sensitive, objective readouts. Acute optic neuritis may represent an interesting paradigm where biologically meaningful outcome parameters can be objectively and sensitively quantified [34]. Finally, our results may also harbor implications for other clinical situations, since GCs are widely used in the treatment of autoimmune disease and malignancies.

Acknowledgements We thank Cathy Ludwig for language editing and Prof. Alan Baxter and Dr. Margaret Jordan (Jams Cook University, Townsville) as well as Dr. Judith Field (Florey Institute, Melbourne) for their help with the human gene analysis. Furthermore, we also thank Sarah Pittlick and Xiomara Pedreiturria for their help in the laboratory and animal facility.

Funding This work was funded by the Swiss National Fund (SNF no. 310030_172952). Parts of the work (human gene analyses) were also supported by NHMRC Project Grant 1032486, NHRMC Practitioner Fellowship (Level A; 1080518; HB) and the MS Research Australia Fellow Ship, which supported MMG.

Open Access This article is distributed under the terms of the Creative Commons Attribution 4.0 International License (http://creativeco mmons.org/licenses/by/4.0/), which permits unrestricted use, distribution, and reproduction in any medium, provided you give appropriate credit to the original author(s) and the source, provide a link to the Creative Commons license, and indicate if changes were made.

\section{References}

1. Anonymous (2017) Summary of medical product characteristics (SPC) Solu-Medrol. Pfizer. http://www.pharmazie.com/graph ic/A/17/0-16217.pdf. Accessed 11 Nov 2018

2. Barnes PJ, Adcock IM (2009) Glucocorticoid resistance in inflammatory diseases. Lancet (London, England) 373:1905-1917. https ://doi.org/10.1016/s0140-6736(09)60326-3

3. Baron JA, Barry EL, Mott LA, Rees JR, Sandler RS, Snover DC et al (2015) A trial of calcium and vitamin D for the prevention of colorectal adenomas. N Engl J Med 373:1519-1530. https://doi. org/10.1056/NEJMoa1500409

4. Becklund BR, Hansen DW Jr, Deluca HF (2009) Enhancement of 1,25-dihydroxyvitamin D3-mediated suppression of experimental autoimmune encephalomyelitis by calcitonin. Proc Natl Acad Sci USA 106:5276-5281. https://doi.org/10.1073/pnas.0813312106

5. Bennett BL, Sasaki DT, Murray BW, O'Leary EC, Sakata ST, Xu W et al (2001) SP600125, an anthrapyrazolone inhibitor of Jun N-terminal kinase. Proc Natl Acad Sci USA 98:13681-13686. https://doi.org/10.1073/pnas.251194298

6. Berkovich R (2013) Treatment of acute relapses in multiple sclerosis. Neurotherapeutics J Am Soc Exp Neurother 10:97-105. https ://doi.org/10.1007/s13311-012-0160-7

7. Cantorna MT, Hayes CE, DeLuca HF (1996) 1,25-Dihydroxyvitamin D3 reversibly blocks the progression of relapsing encephalomyelitis, a model of multiple sclerosis. Proc Natl Acad Sci USA 93:7861-7864 
8. Dankers W, Gonzalez-Leal C, Davelaar N, Asmawidjaja PS, Mus AMC, Hazes JMW et al (2018) 1,25(OH)2D3 and dexamethasone additively suppress synovial fibroblast activation by CCR8(+) $\mathrm{T}$ helper memory cells and enhance the effect of tumor necrosis factor alpha blockade. Arthritis Res Ther 20:212. https://doi. org/10.1186/s13075-018-1706-9

9. Delgoffe GM, Pollizzi KN, Waickman AT, Heikamp E, Meyers DJ, Horton MR et al (2011) The kinase mTOR regulates the differentiation of helper $\mathrm{T}$ cells through the selective activation of signaling by mTORC1 and mTORC2. Nat Immunol 12:295-303. https://doi.org/10.1038/ni.2005

10. Dienstmann R, Rodon J, Serra V, Tabernero J (2014) Picking the point of inhibition: a comparative review of PI3K/AKT/mTOR pathway inhibitors. Mol Cancer Ther 13:1021-1031. https://doi. org/10.1158/1535-7163.mct-13-0639

11. Dubois M, Le Joncour V, Tonon MC, Anouar Y, Proust F, Morin F et al (2014) Evaluation of the impact of the cancer therapy everolimus on the central nervous system in mice. PLoS One 9:e113533. https://doi.org/10.1371/journal.pone.0113533

12. Elenkov IJ (2004) Glucocorticoids and the Th1/Th2 balance. Ann N Y Acad Sci 1024:138-146. https://doi.org/10.1196/annal s.1321.010

13. Gold RHB, Wiendl H (2017) Diagnose und Therapie der Multiplen Sklerose http://www.dgn.org. Accessed 11 Nov 2018

14. Gold SM, Sasidhar MV, Lagishetty V, Spence RD, Umeda E, Ziehn MO et al (2012) Dynamic development of glucocorticoid resistance during autoimmune neuroinflammation. J Clin Endocrinol Metab 97:E1402-1410. https://doi.org/10.1210/ jc.2012-1294

15. Goodin DS (2014) Handbook of clinical neurology multiple sclerosis and related disorders. Elsevier, Amsterdam

16. Herold MJ, Reichardt HM (2013) Glucocorticoid-induced apoptosis in animal models of multiple sclerosis. Crit Rev Immunol 33:183-202

17. Hirst C, Ingram G, Pearson O, Pickersgill T, Scolding N, Robertson N (2008) Contribution of relapses to disability in multiple sclerosis. J Neurol 255:280-287. https://doi.org/10.1007/ s00415-008-0743-8

18. Holick MF (2007) Vitamin D deficiency. N Engl J Med 357:266-281. https://doi.org/10.1056/NEJMra070553

19. Huang J, Manning BD (2008) The TSC1-TSC2 complex: a molecular switchboard controlling cell growth. Biochem J 412:179-190. https://doi.org/10.1042/bj20080281

20. Kabbani TA, Koutroubakis IE, Schoen RE, Ramos-Rivers C, Shah N, Swoger J et al (2016) Association of vitamin D level with clinical status in inflammatory bowel disease: a 5-year longitudinal study. Am J Gastroenterol 111:712-719. https:// doi.org/10.1038/ajg.2016.53

21. Kennel KA, Drake MT, Hurley DL (2010) Vitamin D deficiency in adults: when to test and how to treat. Mayo Clin Proc 85:752757. https://doi.org/10.4065/mcp.2010.0138 (quiz 757-758)

22. Le Page E, Veillard D, Laplaud DA, Hamonic S, Wardi R, Lebrun $C$ et al (2015) Oral versus intravenous high-dose methylprednisolone for treatment of relapses in patients with multiple sclerosis (COPOUSEP): a randomised, controlled, double-blind, non-inferiority trial. Lancet (London, England) 386:974-981. https://doi.org/10.1016/s0140-6736(15)61137-0

23. Leussink VI, Jung S, Merschdorf U, Toyka KV, Gold R (2001) High-dose methylprednisolone therapy in multiple sclerosis induces apoptosis in peripheral blood leukocytes. Arch Neurol 58:91-97

24. Lips $P$ (2007) Relative value of $25(\mathrm{OH}) \mathrm{D}$ and $1,25(\mathrm{OH}) 2 \mathrm{D}$ measurements. J Bone Miner Res 22:1668-1671. https://doi. org/10.1359/jbmr.070716

25. Lisse TS, Liu T, Irmler M, Beckers J, Chen H, Adams JS et al (2011) Gene targeting by the vitamin D response element binding protein reveals a role for vitamin $\mathrm{D}$ in osteoblast mTOR signaling. FASEB J 25:937-947. https://doi.org/10.1096/fj.10172577

26. Lublin FD, Baier M, Cutter G (2003) Effect of relapses on development of residual deficit in multiple sclerosis. Neurology 61:1528-1532

27. Luhder F, Reichardt HM (2009) Traditional concepts and future avenues of glucocorticoid action in experimental autoimmune encephalomyelitis and multiple sclerosis therapy. Crit Rev Immunol 29:255-273

28. Marchetti P, Natoli V, Ranelletti FO, Mandelli F, De Rossi G, Iacobelli S (1981) Glucocorticoid receptor studies in human leukemia. J Steroid Biochem 15:261-268

29. Matysiak M, Makosa B, Walczak A, Selmaj K (2008) Patients with multiple sclerosis resisted to glucocorticoid therapy: abnormal expression of heat-shock protein 90 in glucocorticoid receptor complex. Mult Scler (Houndmills, Basingstoke, England) 14:919-926. https://doi.org/10.1177/1352458508090666

30. Metz I, Weigand SD, Popescu BF, Frischer JM, Parisi JE, Guo $Y$ et al (2014) Pathologic heterogeneity persists in early active multiple sclerosis lesions. Ann Neurol 75:728-738. https://doi. org/10.1002/ana.24163

31. Miller AL, Garza AS, Johnson BH, Thompson EB (2007) Pathway interactions between MAPKs, mTOR, PKA, and the glucocorticoid receptor in lymphoid cells. Cancer Cell Int 7:3. https://doi. org/10.1186/1475-2867-7-3

32. National Center of Biotechnology Information US National Library of Medicine. http://www.ncbi.nlm.nih.gov/gene. Accessed 11 Nov 2018

33. Nickerson M, Cofield SS, Tyry T, Salter AR, Cutter GR, Marrie RA (2015) Impact of multiple sclerosis relapse: the NARCOMS participant perspective. Mult Scler Relat Disord 4:234-240. https ://doi.org/10.1016/j.msard.2015.03.005

34. Petzold A, Wattjes MP, Costello F, Flores-Rivera J, Fraser CL, Fujihara K et al (2014) The investigation of acute optic neuritis: a review and proposed protocol. Nat Rev Neurol 10:447-458. https ://doi.org/10.1038/nrneurol.2014.108

35. Powe CE, Evans MK, Wenger J, Zonderman AB, Berg AH, Nalls $M$ et al (2013) Vitamin D-binding protein and vitamin D status of black Americans and white Americans. N Engl J Med 369:19912000. https://doi.org/10.1056/NEJMoa1306357

36. Prietl B, Treiber G, Pieber TR, Amrein K (2013) Vitamin D and immune function. Nutrients 5:2502-2521. https://doi.org/10.3390/ nu5072502

37. Reichardt HM, Kaestner KH, Tuckermann J, Kretz O, Wessely O, Bock R et al (1998) DNA binding of the glucocorticoid receptor is not essential for survival. Cell 93:531-541

38. Rodriguez JM, Monsalves-Alvarez M, Henriquez S, Llanos MN, Troncoso R (2016) Glucocorticoid resistance in chronic diseases. Steroids 115:182-192. https://doi.org/10.1016/j.stero ids.2016.09.010

39. Rolf L, Damoiseaux J, Hupperts R, Huitinga I, Smolders J (2016) Network of nuclear receptor ligands in multiple sclerosis: common pathways and interactions of sex-steroids, corticosteroids and vitamin D3-derived molecules. Autoimmun Rev 15:900-910. https://doi.org/10.1016/j.autrev.2016.07.002

40. Rommer PS, Buckow K, Ellenberger D, Friede T, PitschnauMichel D, Fuge J et al (2015) Patients characteristics influencing the longitudinal utilization of steroids in multiple sclerosis-an observational study. Eur J Clin Investig 45:587-593. https://doi. org/10.1111/eci.12450

41. Roy PK, Rashid F, Bragg J, Ibdah JA (2008) Role of the JNK signal transduction pathway in inflammatory bowel disease. World J Gastroenterol 14:200-202 
42. Saxton RA, Sabatini DM (2017) mTOR signaling in growth, metabolism, and disease. Cell 168:960-976. https://doi. org/10.1016/j.cell.2017.02.004

43. Schilling S, Linker RA, Konig FB, Koziolek M, Bahr M, Muller GA et al (2006) Plasma exchange therapy for steroid-unresponsive multiple sclerosis relapses: clinical experience with 16 patients. Der Nervenarzt 77:430-438. https://doi.org/10.1007/s0011 5-005-2019-1

44. Schmidt J, Gold R, Schonrock L, Zettl UK, Hartung HP, Toyka KV (2000) T-cell apoptosis in situ in experimental autoimmune encephalomyelitis following methylprednisolone pulse therapy. Brain J Neurol 123(Pt 7):1431-1441

45. Schrewe L, Lill CM, Liu T, Salmen A, Gerdes LA, Guillot-Noel L et al (2015) Investigation of sex-specific effects of apolipoprotein E on severity of EAE and MS. J Neuroinflamm 12:234. https:// doi.org/10.1186/s12974-015-0429-y

46. Schweingruber N, Reichardt SD, Luhder F, Reichardt HM (2012) Mechanisms of glucocorticoids in the control of neuroinflammation. J Neuroendocrinol 24:174-182. https://doi.org/10.111 1/j.1365-2826.2011.02161.x

47. Searing DA, Zhang Y, Murphy JR, Hauk PJ, Goleva E, Leung DY (2010) Decreased serum vitamin D levels in children with asthma are associated with increased corticosteroid use. J Allergy Clin Immunol 125:995-1000. https://doi.org/10.1016/j. jaci.2010.03.008

48. Sloka S, Silva C, Wang J, Yong VW (2011) Predominance of Th2 polarization by vitamin D through a STAT6dependent mechanism. J Neuroinflamm 8:56. https://doi. org/10.1186/1742-2094-8-56

49. Sparagana SP (2016) mTORC1 inhibition for epilepsy in TSC: feasibility in question. Neurology 87:974-975. https://doi. org/10.1212/wnl.0000000000003073

50. Urzua CA, Guerrero J, Gatica H, Velasquez V, Goecke A (2017) Evaluation of the glucocorticoid receptor as a biomarker of treatment response in Vogt-Koyanagi-Harada disease. Investig Ophthalmol Vis Sci 58:974-980. https://doi.org/10.1167/ iovs.16-20783

51. Wang Z, Li P, Zhang Q, Lv H, Liu J, Si J (2015) Interleukin-1beta regulates the expression of glucocorticoid receptor isoforms in nasal polyps in vitro via p38 MAPK and JNK signal transduction pathways. J Inflamm (London, England) 12:3. https://doi. org/10.1186/s12950-014-0046-z

52. Wust S, Tischner D, John M, Tuckermann JP, Menzfeld C, Hanisch UK et al (2009) Therapeutic and adverse effects of a non-steroidal glucocorticoid receptor ligand in a mouse model of multiple sclerosis. PLoS One 4:e8202. https://doi.org/10.1371/ journal.pone.0008202

53. Wust S, van den Brandt J, Reichardt HM, Luhder F (2012) Preventive treatment with methylprednisolone paradoxically exacerbates experimental autoimmune encephalomyelitis. Int J Endocrinol 2012:417017. https://doi.org/10.1155/2012/417017

54. Wust S, van den Brandt J, Tischner D, Kleiman A, Tuckermann JP, Gold R, Luhder F et al (2008) Peripheral T cells are the therapeutic targets of glucocorticoids in experimental autoimmune encephalomyelitis. J Immunol (Baltimore, Md: 1950) 180:8434-8443

55. Xystrakis E, Kusumakar S, Boswell S, Peek E, Urry Z, Richards DF, Adikibi T et al (2006) Reversing the defective induction of IL10 -secreting regulatory $\mathrm{T}$ cells in glucocorticoid-resistant asthma patients. J Clin Investig 116:146-155. https://doi.org/10.1172/ jci21759

56. Zeitelhofer M, Adzemovic MZ, Gomez-Cabrero D, Bergman P, Hochmeister S, N'Diaye M et al (2017) Functional genomics analysis of vitamin D effects on CD4+ T cells in vivo in experimental autoimmune encephalomyelitis. Proc Natl Acad Sci USA 114:E1678-e1687. https://doi.org/10.1073/pnas.1615783114

57. Zhang Y, Leung DY, Goleva E (2014) Anti-inflammatory and corticosteroid-enhancing actions of vitamin $\mathrm{D}$ in monocytes of patients with steroid-resistant and those with steroid-sensitive asthma. J Allergy Clin Immunol 133:1744-1752.e1741. https:// doi.org/10.1016/j.jaci.2013.12.004

Publisher's Note Springer Nature remains neutral with regard to jurisdictional claims in published maps and institutional affiliations. 